\title{
Excitotoxic median raphe lesions aggravate working memory storage performance deficits caused by scopolamine infusion into the dentate gyrus of the hippocampus in the inhibitory avoidance task in rats
}

\section{E. Babar,}

E. Melik and

T. Özgünen

\author{
Division of Neurophysiology, Department of Physiology, M edical Faculty, \\ University of Çukurova, Balcali-Adana, Turkey
}

\section{Correspondence \\ E. Babar \\ Department of Physiology \\ Medical Faculty \\ University of Çukurova \\ 01330 Balcali-Adana \\ Turkey \\ Fax: + 90-322-338-6847 \\ E-mail: ebabar@mail.cu.edu.tr}

Received July 25, 2001

Accepted February 28, 2002

\section{Abstract}

The interactions between the median raphe nucleus (MRN) serotonergic system and the septohippocampal muscarinic cholinergic system in the modulation of immediate working memory storage performance were investigated. Rats with sham or ibotenic acid lesions of the MRN were bilaterally implanted with cannulae in the dentate gyrus of the hippocampus and tested in a light/dark step-through inhibitory avoidance task in which response latency to enter the dark compartment immediately after the shock served as a measure of immediate working memory storage. MRN lesion per se did not alter response latency. Post-training intrahippocampal scopolamine infusion (2 and $4 \mu \mathrm{g}$ / side) produced a more marked reduction in response latencies in the lesioned animals compared to the sham-lesioned rats. Results suggest that the immediate working memory storage performance is modulated by synergistic interactions between serotonergic projections of the MRN and the muscarinic cholinergic system of the hippocampus.

\section{Introduction}

There is considerable evidence suggesting that the interactive processes between the serotonin (5-HT) and acetylcholine (ACh) systems are severely affected in a majority of Alzheimer's disease cases (1-3). The abnormalities in interactive neurotransmitter processes may be a factor causing cognitive impairments such as working memory deficits in this disease $(4,5)$. Behavioral studies

\section{Key words}

- Working memory

- Median raphe nucleus

- Serotonin

- Scopolamine

- Acetylcholine

- Inhibitory avoidance have provided strong evidence for the involvement of the 5-HT and ACh systems in working memory $(6,7)$. It is well known that the hippocampus is a critical structure for the interaction of 5-HT and ACh systems and for the mediation of working memory (8-12). However, the nature of the interactions between these systems in the hippocampus remains unclear $(7,9,10,13)$.

The hippocampus receives extensive innervations from polygonal serotonergic cell 
bodies (14) in the dorsal and median raphe nuclei (MRN) $(15,16)$ and contains multiple 5-HT receptor subtypes (17). Therefore, it has been proposed that the interactions between the septohippocampal 5-HT and ACh in the modulation of learning and memory may depend on serotonergic origins $(18,19)$ and specification of 5-HT receptors (17). It is believed that tasks assessing working memory should be able to distinguish the non-mnemonic changes from mnemonic processes within one session $(10,20)$ and also distinguish the formation and storage of immediate memory lasting seconds or a few minutes $(8,21)$. The immediate memory in a single-trial inhibitory avoidance test is now identified as working memory (21-23).

In the present study, using a single-trial step-through inhibitory avoidance task, we examined the effects of neurotoxic lesions of the MRN on immediate memory deficits resulting from post-training scopolamine infusion into the dentate gyrus of the dorsal hippocampus which is a MRN-innervated area (24), and thereby tried to determine if the MRN-serotonergic system regulates immediate working memory storage performance by interacting with the septohippocampal muscarinic cholinergic system.

\section{Material and Methods}

\section{Animals}

Adult male Wistar rats weighing 220$250 \mathrm{~g}$ were maintained under a 12-h lightdark (lights on at 7:00 h) illumination cycle with free access to food and water. The animals were handled and allowed to adapt to the experimental room and were habituated to the infusion procedure for 5 days.

\section{Inhibitory avoidance testing}

Behavioral tests were carried out using a step-through inhibitory avoidance apparatus as described previously (25). In the training trial, when the rats were placed in the testing illuminated compartment, they escaped to the dark compartment. The initial escape from the illuminated compartment to the dark box was considered as escape latency and was taken as a measure of non-mnemonic behaviors in a new context. When all four paws were on the shock grid floor of the dark compartment, the door was lowered and after a 3-s delay, a 1.0-mA scrambled footshock was applied to the grid floor for $2 \mathrm{~s}$. The rat then was immediately removed from the dark compartment and $10 \mathrm{~min}$ after the shock, again placed in the testing compartment without shock and allowed access to the dark compartment for a maximum of $300 \mathrm{~s}$. The time to step into the dark compartment (response latency) was used as a measure of working memory. The response latency value of $300 \mathrm{~s}$ was assigned when the rat did not enter the dark compartment within $300 \mathrm{~s}$. The chamber was cleaned with $5 \%$ alcohol and tap water between rats. Inhibitory avoidance training and testing were performed from 9:00 to 12:00 h.

\section{Surgery}

Before the behavioral experiments, all rats $(\mathrm{N}=54)$ were randomly divided into sham- and MRN-lesioned groups. Each rat was placed in a stereotaxic frame under sodium pentobarbital anesthesia $(45 \mathrm{mg} / \mathrm{kg}$, ip $)$ and $2 \mu \mathrm{l}$ of ibotenic acid $(1 \mu \mathrm{g} / \mu \mathrm{l}$, Sigma I2765, St. Louis, MO, USA) or artificial cerebrospinal fluid (aCSF) (in sham-lesioned rats) was infused through a stainless steel infusion cannula (24 gauge) into the MRN region, as described previously (26). In the same rats, guide cannulae (21 gauge) were implanted bilaterally into the dorsal hippocampus $1 \mathrm{~mm}$ above the dentate gyrus for microinfusion of the drug. The following stereotaxic coordinates were used: $3.8 \mathrm{~mm}$ posterior to bregma, $2.0 \mathrm{~mm}$ lateral to midline and $2.0 \mathrm{~mm}$ ventral to the bone surface of the skull according to the brain atlas of 
Paxinos and Watson (27). The hippocampal guide cannulae were fixed to the skull with two stainless steel screws and dental cement and closed with removable silicon plugs. Animals were allowed to recover for 20 days before being tested in the inhibitory avoidance task.

\section{Drug and intrahippocampal infusion}

The cholinergic muscarinic antagonist (-)-scopolamine hydrobromide (Sigma) was used and prepared fresh on each trial day in aCSF. Vehicle (aCSF) infusion was used as control treatment.

Immediately after the shock (one minute delay), sham- and MRN-lesioned rats were restrained by hand and an infusion cannula was fitted into the guide cannula. The tip of the infusion cannula protruded $1 \mathrm{~mm}$ beyond the guide cannula and was aimed at the granular layer of the dentate gyrus. Animals received a bilateral $1-\mu 1$ infusion of vehicle or scopolamine ( 2 or $4 \mu \mathrm{g} / \mathrm{side}$ ) through the infusion cannula. The drug was used in a dose range previously shown to produce a marked working memory deficit in the inhibitory avoidance task (23). Infusion was performed with a pump (Cole Palmer, Model 210) at a rate of $0.5 \mu 1 / \mathrm{min}$. The infusion cannula was left in place for another $30 \mathrm{~s}$ after completion of the infusion. The entire infusion procedure took about $5 \mathrm{~min}$. After infusion, all rats were placed in their home cages for $5 \mathrm{~min}$ in order to minimize stress.

\section{Histology}

Shortly after the behavioral tests, rats were deeply anesthetized with sodium pentobarbital, and perfused intracardially with $0.9 \% \mathrm{NaCl}$ followed by $10 \%$ formalin. The brains were further fixed in $10 \%$ formalin and sectioned along the coronal plane (5-50 $\mu \mathrm{m})$. These sections were assessed for tissue lesion in the MRN and for location of the tip of the guide cannulae in the dorsal hippo-

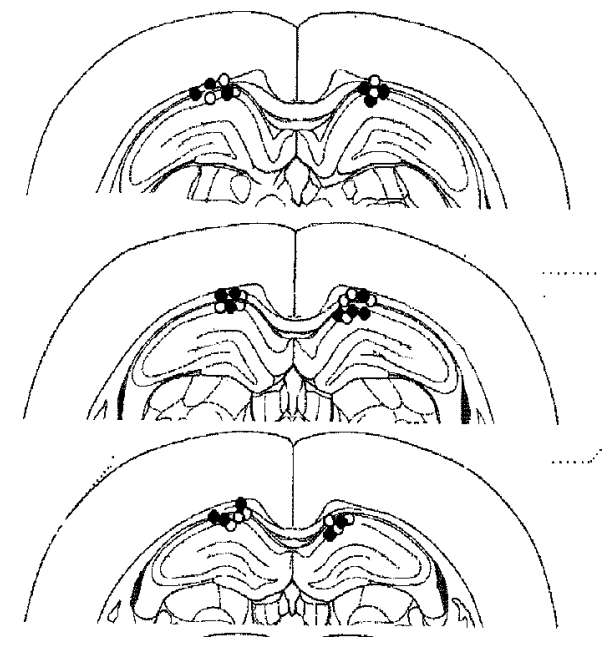

Figure 1. Brain sections in the coronal plane showing the tips of the guide cannulae in rats infused with $2 \mu \mathrm{g}$ scopolamine (open circles) and $4 \mu \mathrm{g}$ scopolamine (filled circles). Plates adapted from the rat brain atlas of Paxinos and Watson (27).

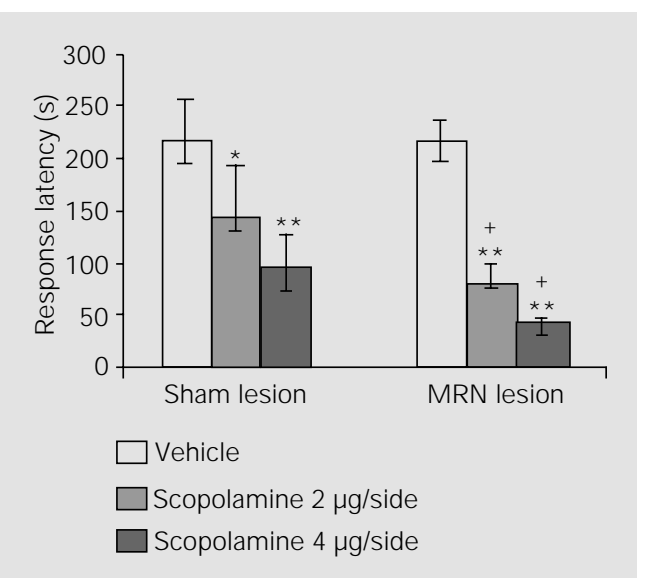

campus. As shown previously, ibotenic acid at the dose used resulted in marked polygonal cell body loss in the MRN regions (26). The ventral positions of the tips of the guide cannulae ranged approximately from 2.0 to $2.3 \mathrm{~mm}$ (Figure 1), indicating that the infusion cannulae were positioned between 3.0$3.3 \mathrm{~mm}$, i.e., in the dentate gyrus at the time of infusion. Data from no animal had to be discarded due to poor placement.

\section{Statistical analysis}

Results are reported as medians and interquartile ranges. Data were analyzed statistically by Kruskal-Wallis analysis of variance followed by the Mann-Whitney $U$-test.
Figure 2. Effects of post-training intrahippocampal infusion of scopolamine on response latencies in sham- and median raphe nucleus (MRN)-lesioned rats. Each column represents the median (interquartile ranges). Kruskal-Wallis analysis of variance for post-training scopolamine infusion in sham-lesioned groups $[\mathrm{H}(2, \mathrm{~N}=27)=18.4$, $\mathrm{P}<0.001]$ and in MRN-lesioned groups $[\mathrm{H}(2, \mathrm{~N}=27)=23.1$, $\mathrm{P}<0.0001]$. $* \mathrm{P}<0.05, * * \mathrm{P}<0.001$ compared to vehicle control; $+\mathrm{P}<0.001$ compared to sham control (Mann-Whitney U-test). $\mathrm{N}=9$ animals in all groups. 
$\mathrm{P}<0.05$ was used as the criterion for statistical significance.

\section{Results}

The escape latencies for sham- and MRNlesioned rats were quite similar (overall mean, $24 \mathrm{~s}$; median, $21 \mathrm{~s} ; \mathrm{N}=54)$; the difference was not statistically significant $[\mathrm{H}(5, \mathrm{~N}=$ $54)=2.17, P=0.82]$, indicating that $\mathrm{MRN}$ lesion per se had no effect on non-mnemonic behaviors in a new context. As seen in Figure 2, MRN lesion per se did not alter response latency $[\mathrm{H}(1, \mathrm{~N}=18)=0.048, \mathrm{P}=$ 0.82 ], indicating that $\mathrm{MRN}$ lesion had no effect on the performance of working memory in the inhibitory avoidance task. Post-training scopolamine at both dose levels ( 2 and 4 $\mu \mathrm{g} /$ side) significantly decreased response latencies of both sham- and MRN-lesioned animals, but a more dramatic decrease was observed in the MRN-lesioned animals (Figure 2). This indicates that MRN lesions aggravated the post-training scopolamine-induced reduction in the immediate storing performance of working memory.

\section{Discussion}

The present results demonstrate that in rats with an intact cholinergic system, neurotoxic damage to the polygonal serotonergic cell bodies in the MRN region had no effect on immediate storage of working memory in the inhibitory avoidance task per se. These findings are in agreement with other studies reporting no changes in the learning and memory processes following serotonergic pathway blockade in the midbrain $(6,28-30)$. The present study also showed that MRN lesions aggravated working memory deficits evoked by post-training intrahippocampal scopolamine infusion. The lack of effect of MRN lesions on non-mnemonic index such as escape latency clearly indicated that the effect of lesions on scopolamine-induced working memory deficits was not due to the increased locomotor activity. Earlier, we showed that ibotenic MRN lesions had no effect on innate one-way escape latency (25) or on immediate freezing conditioning (26). It is important to note that MRN lesions did not alter response latencies in the vehicletreated animals, an effect that precluded the alteration in footshock sensitivity as a cause of deeper working memory deficits seen in the MRN-lesioned rats under the influence of the drug.

The demonstration of an aggravating effect of MRN lesion on post-training scopolamine-induced working memory storage deficit is consistent with many reports. For instance, 5,7-dihydroxytryptamine injections into the fimbria-fornix that prevent 5-HT influence originating from the MRN, in combination with median septum lesions, produce deeper memory deficits than those induced by median septum lesion alone $(8,9)$. Pre-training p-chloroamphetamine administration to produce 5-HT depletion in the midbrain, which by itself has no effect, potentiates the disruptive effects of scopolamine when given immediately after training (31). All arguments presented indicate a clear synergistic interaction between serotonergic and muscarinic AChergic systems in the regulation of storing performance of working memory in the inhibitory avoidance.

There is evidence confirming the view that the septohippocampal formation is important for the selection and regulation of the salience of environmental stimuli (32) and supporting temporal storage of neuronal representation of the contextual cues $(33,34)$. Neuroanatomical studies indicate that serotonergic inputs modulate septohippocampal muscarinic AChergic networks via direct connection with the muscarinic-AChergic cell bodies, and exert indirect modulation on these networks through the hippocampal GABAergic interneurons $(35,36)$. Through hippocampal GABAergic interneurons, serotonergic inputs modulate the activity of glutamate receptors, which is related to memory 
storage (36,37). Izquierdo et al. (23) showed that hippocampal AMPA receptor-mediated glutamatergic transmission, which is susceptible to GABA inhibition, is necessary for working memory retrieval in the inhibitory avoidance task. Furthermore, Ohno et al. (38) reported that intrahippocampal infusion of a competitive NMDA-receptor antagonist such as CPP impairs working memory performance of rats in a tree-panel runway task. Thus, taken together, these data suggest that through the GABAergic interneurons in the septohippocampal formation, MRN-serotonergic projections indirectly modulate excitation of neuronal networks related to immediate associations of contextual cues. It has been reported that AChergic and glutamatergic systems are functionally linked to the mediation of learning and memory. Markram and Segal (39) found that, in hippocampal slices, ACh amplified NMDA-related excitatory postsynaptic potentials by acting on muscarinic receptors. Ohno and Watanabe (40) showed that low doses of scopolamine and of the non-competitive NMDA receptor antagonist MK-801, each ineffective when administered alone, significantly impaired inhibitory avoidance when administered simultaneously. Hence, we suggest that blockade of inhibitory influence of MRN-serotonergic projections leads to disinhibition of GABAergic interneurons of the hippocampus, resulting in attenuation of NMDA or AMPA receptor-related mnemonic mechanisms. Perhaps, in the case of intact muscarinic receptor-related mechanisms of working memory in the inhibitory avoidance task, MRN lesions fail to prevent the formation of immediate memory storage, whereas in combination with muscarinic receptor blockade, MRN lesions aggravate working memory deficits due to the additional impairment in the glutamate receptorrelated mechanisms of working memory.

The aggravating effects of MRN lesions on the scopolamine-induced immediate memory deficits in the inhibitory avoidance task provide evidence suggesting that MRN projections are important in the regulation of mnemonic processes related to muscarinic AChergic mechanisms of working memory in the hippocampus, at least in the dentate gyrus.

\section{References}

1. Mann DMA \& Yates PO (1983). Neurotransmitter deficits in Alzheimer's disease and in other demanding disorders. Human Neurobiology, 5: 147-158.

2. Collection D (1986). Cholinergic function and intellectual decline in Alzheimer's disease. Neuroscience, 19: 1-28.

3. Chan-Palay V, Huchli M, J entsch B, Leonard B \& Zetzche T (1992). Raphe serotonin neurons in the human brain stem in normal controls and patients with senile dementia of the Alzheimer type and Parkinson's disease: relationship to monoamine oxidase enzyme localisation. Dementia, 3: 253-269.

4. Miller E (1973). Short- and long-term memory in patients with presenile dementia (Alzheimer's disease). Psychological Medicine, 3: 221-224.

5. Mitrushina $M$, Drebing $C$, Uchiyama $C$, Satz P, Van Gorp W \& Chervinsky A
(1994). The pattern of deficit in different memory components in normal aging and dementia of Alzheimer's type. J ournal of Clinical Psychology, 50: 591-596.

6. Nilsson OG, Strecker RE, Daszuta A \& Bjorlund A (1988). Combined cholinergic and serotonergic denervation of the forebrain produces severe deficits in a spatial learning task in the rat. Brain Research, 453: 235-246.

7. Santucci AC, Moody E \& Demetriades J (1995). Effects of scopolamine on spatial working memory in rats pre-treated with the serotonergic depleter p-chloroamphetamine. Neurobiology of Learning and Memory, 63: 286-290.

8. Richter-Levin G, Greenberger V \& Segal $M$ (1994). The effects of general and restricted serotonergic lesions on hippocampal electrophysiology and behavior. Brain Research, 642: 111-116.
9. Murtha SJ E \& Pappas BA (1994). Neurochemical, histopathological and mnemonic effects of combined lesions of the medial septal area and serotonin afferents to the hippocampus. Brain Research, 651: 16-26.

10. Ohno M \& Watanabe S (1996). Blockade of 5-HT1A receptors compensates loss of hippocampal cholinergic neurotransmission involved in working memory of rats. Brain Research, 736: 180-188.

11. Izquierdo I, Medina J H, Izquierdo LA, Barros DM, de Souza MM \& Mello e Souza $\mathrm{T}$ (1998). Short- and long-term memory are differently regulated by monoaminergic systems in the rat brain. Neurobiology of Learning and Memory, 69: 219-224.

12. Izquierdo I, Medina JH, Vianna MRM, Izquierdo LA \& Barros DM (1999). Separate mechanisms for short- and long-term memory. Behavioural Brain Research, 
103: 1-11.

13. Sakurai Y \& Wenk GL (1990). The interaction of acetylcholinergic and serotonergic neuronal systems on performance in a continuous non-matching to sample task. Brain Research, 519: 118-121.

14. Taber E, Brodal A \& Walberg F (1960). The raphe nuclei of the brain stem of the cat. J ournal of Comparative Neurology, 114: 161-168.

15. Azmita EC \& Segal M (1978). An autoradiographic analysis of the ascending projection of the dorsal and median raphe nucleus in the rat. J ournal of Comparative Neurology, 179: 641-668.

16. Mokler DJ, Lariviere D, J ohnson DW, Theriault NL, Bronzino J D, Dixon M \& Morgane PJ (1998). Serotonin neuronal release from dorsal hippocampus following electrical stimulation of the dorsal and median raphe nuclei in conscious rats. Hippocampus, 8: 262-273.

17. Oleskevich $S \&$ Descarries L (1990). Quantified distribution of the serotonin innervation in adult rat hippocampus. Neuroscience, 34: 19-33.

18. Solomon PR, Nichols GL, Kiernan 3rd J M, Kamer RS \& Kaplan LJ (1980). Differential effects of lesions in median and dorsal raphe of the rat: Latent inhibition and septohippocampal serotonin level. J ournal of Comparative Physiology and Psychology, 94: 145-154.

19. Buhot MCh (1997). Serotonin receptors in cognitive behaviors. Current Opinion in Neurobiology, 7: 243-254.

20. Dunnett SB (1993). Operant delayed matching a non-matching to position in rats. In: Sahgal A (Editor), Behavioral Neuroscience, A Practical Approach. Vol. 1. Oxford University Press, Oxford, UK, 123136.

21. Gold PE \& McGaugh J L (1975). A singletrace, two-process view of memory storage processes. In: Deutsch D \& Deutsch J A (Editors), Short-term Memory. Academic Press, New York, NY, USA, 355378.

22. Izquierdo I, Barros DM, Mello e Souza T, de Souza MM, Izquierdo LA \& Medina J H (1998). Mechanisms for memory types differ. Nature, 393: 635-636.

23. Izquierdo I, Izquierdo LA, Barros DM, Mello e Souza T, de Souza MM, Quevedo $\mathrm{J}$, Rodrigues C, Sant'Anna MK, Madruga M \& Medina JH (1998). Differential involvement of cortical receptor mechanisms in working, short- and long-term memory. Behavioural Pharmacology, 9: 421-427.

24. Roberts C, Belenguer A, Middlemiss DN $\&$ Roultledge C (1998). Differential effects of $5-\mathrm{HT}_{1 \mathrm{~B} / 1 \mathrm{D}}$ receptor antagonists in dorsal and median raphe innervated brain regions. European J ournal of Pharmacology, 346: 175-180.

25. Babar E, Özgünen T, Melik E, Polat $S \&$ Akman H (2001). Effects of ketamine on different types of anxiety/fear and related memory in rats with lesions of the median raphe nucleus. European J ournal of Pharmacology, 431: 315-320.

26. Melik EM, Babar-Melik E, Ozgunen T \& Binokay S (2000). Median raphe nucleus mediates forming long-term but not shortterm contextual fear conditioning in rats. Behavioural Brain Research, 112: 145150.

27. Paxinos G \& Watson C (1982). The Rat Brain in Stereotaxic Coordinates. Academic Press, New York, NY, USA.

28. Richter-Levin G \& Segal M (1989). Spatial performance is severely impaired in rats with combined reduction of serotonergic and cholinergic transmission. Brain Research, 477: 404-407.

29. Riekkinen $M$, Riekkinen $P$, Sirvio J \& Riekkinen J r P (1992). Effects of combined methysergic and mecamylamine/ scopolamine treatment on spatial navigation. Brain Research, 585: 322-326.

30. Dringenberg HC \& Zalan RM (1999). Serotonin-dependent maintenance of spatial performance and EEG activation after cholinergic blockade: effects of serotonergic receptor antagonists. Brain Research, 837: 242-253.

31. Vanderwolf CH \& Penava D (1992). Potentiation of the effects of antimuscarinic drugs on behavior by serotonin depletion: specificity and relation to learning and memory. In: Levin ED, Decker MW \&
Butcher LI (Editors), Neurotransmitter Interactions and Cognitive Function. Birkhauser, Boston, MA, USA, 257-276.

32. Shors TJ \& Matzel LD (1997). Long-term potentiation: What's learning got to do with it? Behavioural and Brain Sciences, 20: 597-655.

33. Holland PC \& Bouton ME (1999). Hippocampus and context in classical conditioning. Current Opinion in Neurobiology, 9: 195-202.

34. Maren S \& Holt W (2000). The hippocampus and contextual memory retrieval in Pavlovian conditioning. Behavioural Brain Research, 110: 97-108.

35. Hall MD, El Mestikawy S, Emerit MB Pichat L, Hamon M \& Gozlan H (1985). [3H)8-Hydroxy-2-(di-n-propylamino) tetralin binding to pre- and postsynaptic 5-hydroxytryptamine sites in various regions of the rat brain. J ournal of Neurochemistry, 44: 1685-1696.

36. Freund TF, Gulyas Al, Acsady L, Gores T $\&$ Toth K (1990). Serotonergic control of the hippocampus via local inhibitory interneurons. Proceedings of the National Academy of Sciences, USA, 87: 85018505.

37. Matsuyama S, Nei K \& Tanaka S (1997) Regulation of GABA release via NMDA and 5 -HT1A receptors in guinea pig dentate gyrus. Brain Research, 761: 105-112.

38. Ohno $M$, Yamamoto $T \&$ Watanabe $S$ (1992). Effects of intrahippocampal injections of N-methyl-D-aspartate receptor antagonists and scopolamine on working and reference memory assessed in rats by a three-panel runway task. J ournal of Pharmacology and Experimental Therapeutics, 263: 943-950.

39. Markram H \& Segal M (1990). Long-lasting facilitation of excitatory postsynaptic potentials in the rat hippocampus by acetylcholine. J ournal of Physiology, 427: 381-393.

40. Ohno M \& Watanabe S (1996). Interactive processing between glutamatergic and cholinergic systems involved in inhibitory avoidance learning of rats. European J ournal of Pharmacology, 312: 145-147. 